\title{
Accuracy of Land Parcel Area Measurement
}

\section{Introduction}

One of the issues pursued in the framework of geodetic activity is the determination of the surface of various objects. These objects are usually parcels of land and the measurements are made for the needs of agriculture, administration and fiscal. In Europe - due to the introduction of unified subsidies to agriculture - there is a need of monitoring of the sown area [17]. The EU - wide millions of parcels of land are measured each year. At least $5 \%$ of farms are measured for an inspection [8]. In Poland tens of thousands of control measurement of farms applying for subsidies to agriculture are made each year. For example, in 2006 more than 98 thousand farms were indicated for inspections [5].

Control measurements of crops area are carried out either by digitizing the surface imagery (satellite images or aerial photogrammetry) or by direct measurements in the field [14].

Direct measurements of an area on side can be performed with classic geodetic method starting from sideband gauge up to measurements using Total Station, which support the indication of surface measurements relevant programs [13]. Also, the GPS system gives great opportunities in this range $[9,16]$.

Many years ago satellite technology came into general use in many areas of human life many years ago. The army, transport, agriculture, and the extractive industry use satellite technology every day - practically are dependent upon them. Also, in geodesy has been a significant turning point in an application of these technologies [11]. Yet not so long ago measurements with GPS technology were recognized as modern and innovative and now have became a common and basic. Basic factors of the rate of development of these technologies are: reducing the cost of their use and giving access to services ensuring sufficient accuracy [1].

\footnotetext{
* University of Agriculture in Krakow, Department of Land Surveying, Krakow, Poland
} 
Depending on the required accuracy, various satellite receivers and various measurement technologies are used. Not only specialised tools but also manual navigation receivers can be used in geodesy [19]. Concerning measurement needed for subsidies to agriculture manual navigation receivers are used. These receivers do not have high accuracy and for most of geodetic measurements are not suitable for use but some of geodetic works - thanks to the proper method - let them be useful in geodesy [2]. Navigation receivers are useful with a large number of measurements that can be made annually in the EU and with not very high demands of accuracy. Measurement procedure is to register a trace of displacement of receiver along the parcel borders. The sequence of route points (points on the edge of measured area) is registered inside the receiver. There are two types of information at the operator's disposal: characteristic points and the results of constant measurement in fixed interval time. Directly in an area you can obtain an information concerning a surface of land parcel and a number of measurements which has been proceeded. It is obtainable on the basis of trace characteristic points. Second possibility is to calculate a surface from the points in fixed interval of time after the data is transferred into computer. In this case with a large number of measurements data should be copied into a computer right in area (limited quantity of registered traces).

Making an analysis of accuracy of surface indication with consideration of theoretical precision possible to obtain with surveying equipment you will see many discrepancies. It seems that the basic reason of the above is incorrect identifying of parcel land border. To check this point some measurements with manual GPS receivers have been done. Also, some measurements with Total Station took a place. A grass around 0.30 has been used as a test field, the territory of this grass did not have a rectilinear border. Moreover, another important factor could influence on obtained results is the lack of geodetic education of people engaged in measurements and a lack of a reliable treatment of measurement activity.

\section{Accuracy of an Area Indication}

An error in value indication is connected with many factors which influence unfavorably on the accuracy of measurements. All errors can be grouped as follow: incidental, systematic and considerable [3]. This classification can be further divided depending on the specifics of the measurement. Making an analysis of value accuracy on the basis of measurements it is necessary to make an assumption of systematic and considerable error elimination at the stage of initial result elaboration. An error would depend mainly on: chosen measurement technology, chosen equipment, conditions of measurements, personal predisposition of engaged people.

Let's make an assumption that we want to indicate an area of parcel land which has a polygonal shape. Such a linear figure (Fig. 1) is limited by closed broken line with some segments and vertices. 


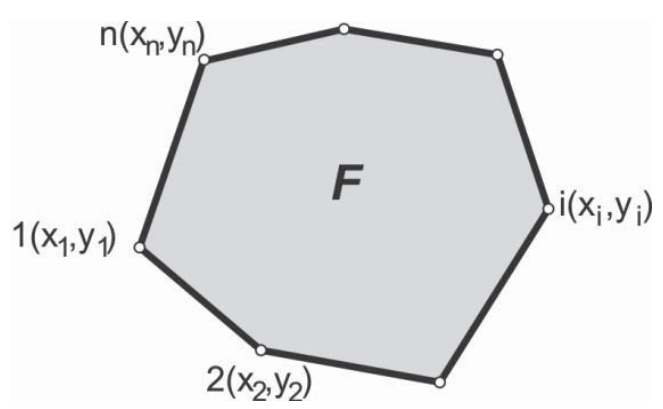

Fig. 1. Area calculation diagram with Cartesian coordinates

In general case to indicate an area of this figure, coordinates of vertices must be measured in an arbitrary co-ordinate system. For a linear figure, each vertex is indicated by two coordinates:

$$
\underset{i=1,2, \ldots, n}{\forall} B_{i}=B\left(a_{i}, b_{i}\right) \in \mathrm{bd} F
$$

where $B$ is a limiting point of $F$ figure (vertex) with linear coordinates a and $b$. Let's assume that we know - thanks to measurements - the average value for each point and each coordinate and average errors which can occur:

$$
\begin{aligned}
& a_{i}=\bar{a}_{i} \pm \sigma_{a_{i}} \\
& b_{i}=\bar{b}_{i} \pm \sigma_{b_{i}}
\end{aligned}
$$

that means we know an error of location of each vertex indicated by measurement:

$$
\sigma_{B_{i}}=f\left(\sigma_{a_{i}}, \sigma_{b_{i}}\right)
$$

Dependency (3) refers to general case, but in practice all sets of assumptions concerning the simplification of accuracy analysis is assumed.

According to previous assumption an area $S$ of $F$ figure is a function of coordinates of its all vertices:

$$
S=g\left(a_{1}, a_{2}, \ldots, a_{n}, b_{1}, b_{2}, \ldots, b_{n}\right)
$$

therefore an error in the indicated area will be also a function of errors of the following coordinates. In order to compute this error a propagation of errors will be applied [6]. For dependency (4) a propagation of errors is the following (coordinates a and $b$ not correlated):

$$
\sigma_{S}^{2}=\sum_{i=1}^{n}\left[\left(\frac{\partial g}{\partial a_{i}}\right)^{2} \sigma_{a_{i}}^{2}+\left(\frac{\partial g}{\partial b_{i}}\right)^{2} \sigma_{b_{i}}^{2}\right]
$$


Let's assume we have to indicate a lateral area $S$ of $F$ figure (Figs 1,2) with edge consists of $n$ of $B_{\mathrm{i}}$ vertices and we know their coordinates. As a result of geodetic measurements using GPS and the pole method with Total Station we obtain the coordinates of vertices in two systems: pole and Cartesian. In other part of elaboration we will focused on these two measurement - analytical methods. Let's assume anticlockwise vertices numeration.

In the case of GPS measurements we obtain orthogonal coordinates of figure vertices in an assumed co-ordinate system (Fig. 1). Computation is done according to the Gauss' area formula $[7,18]$.

There are two formulas at our disposal which can be used exchangeably. For a figure $F$ (Fig. 1) applying orthogonal coordinates to (4) gives:

$$
S=\frac{1}{2} \sum_{i=1}^{n} x_{i}\left(y_{i-1}-y_{i+1}\right) \quad \text { and } \quad y_{0}=y_{n}, \quad y_{n+1}=y_{1}
$$

Location error of $i$-point for orthogonal coordinates on base (3) is equal:

$$
\sigma_{B_{i}}=\sqrt{\sigma_{x_{i}}^{2}+\sigma_{y_{i}}^{2}}
$$

Having exactly the same errors in both coordinates we achieve:

$$
\sigma_{x_{i}}=\sigma_{y_{i}}=\sigma \Rightarrow \sigma_{B_{i}}=\sigma \sqrt{2}
$$

Let's apply a propagation of errors (5) in relation to (6). Making differentiation of dependence (6) and putting (5) to dependence (7) and (8), additionally with the assumption of the same error for all points we obtain:

$$
\sigma_{S}=\sigma_{B} \sqrt{\sum_{i=1}^{n} \frac{\left(x_{i-1}-x_{i+1}\right)^{2}+\left(y_{i-1}-y_{i+1}\right)^{2}}{8}}
$$

where:

$$
\begin{aligned}
& \sigma_{B}=\sigma_{B_{i}}=\text { const }, \quad i=1,2, \ldots, n, \\
& x_{0}=x_{n}, \quad y_{0}=y_{n}, \\
& x_{n+1}=x_{1}, \quad y_{n+1}=y_{1} .
\end{aligned}
$$

Above formula let to track an area error when we know coordinates and an average error of vertices location in orthogonal co-ordinate system.

In the second case let's consider a measurement and computation for pole coordinates system. A direction and a distance is indicated from $P$ pole point (a stand of instrument) to each measure vertex point of $F$ figure (Fig. 2). 


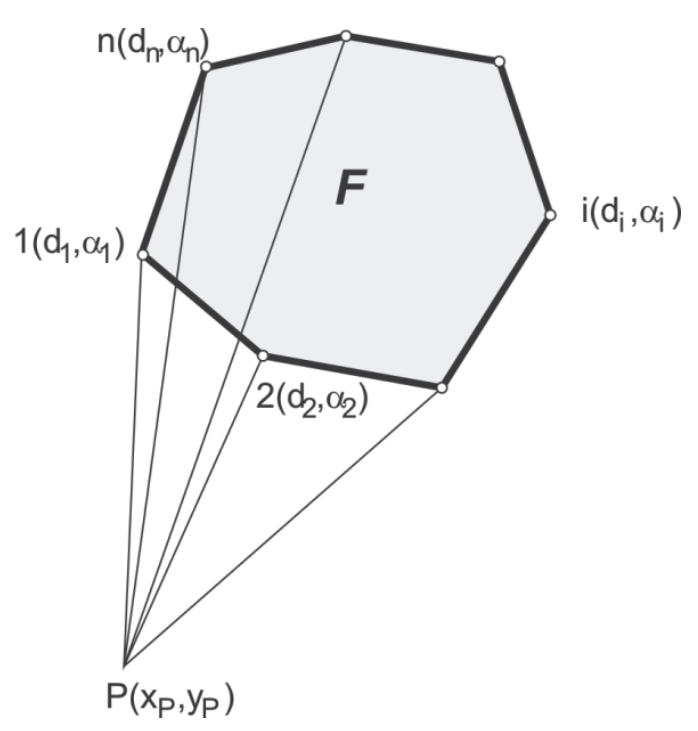

Fig. 2. Area calculation diagram with pole coordinates

For the pole coordinates, according to figure 2, a surface of figure $S$ is equal of a sum of all triangles engaged by one vertex in $P$ pole:

$$
S=\frac{1}{2} \sum_{i=1}^{n} d_{i} d_{i+1} \sin \left(\alpha_{i+1}-\alpha_{i}\right) \quad \text { and } \quad d_{n+1}=d_{1}, \alpha_{n+1}=\alpha_{1}
$$

Location error of $i$-point for pole coordinates with the assumption of faultlessness of the $P$ pole is:

$$
\sigma_{B_{i}}=\sqrt{\sigma_{d_{i}}^{2}+\left(d_{i} \frac{\sigma_{\alpha_{i}}}{\rho}\right)^{2}}
$$

making an assumption of equal error distribution for both coordinates we obtain:

$$
\sigma_{d_{i}}=d_{i} \frac{\sigma_{\alpha_{i}}}{\rho}=\sigma \Rightarrow \sigma_{B_{i}}=\sigma \sqrt{2}
$$

We will apply again a propagation of error (5) this time in relation to (10). We indicate partial derivatives from (10) on all pole coordinates and we put to (5) the dependences (11) and (12), which - with an assumption of the same average error for all points - makes that we obtain [4]:

$$
\sigma_{S}=\frac{1}{2} \sigma_{B} \sqrt{\sum_{i=1}^{n}\left[d_{i}^{2}-d_{i-1} d_{i+1} \cos \left(\alpha_{i+1}-\alpha_{i-1}\right)\right]}
$$


In equation (13):

$\sigma_{B}=\sigma_{B_{i}}=$ const $, \quad i=1,2, \ldots, n$,

$d_{0}=d_{n}, \quad \alpha_{0}=\alpha_{n}$,

$d_{n+1}=d_{1}, \quad \alpha_{n+1}=\alpha_{1}$.

For an allotment indication it is often necessary to estimate an area error without detailed computation. In the literature you can find a formula [10]:

$$
\sigma_{S}=\sigma_{B} \sqrt{S \frac{1+k^{2}}{2 k}}
$$

where $k$ is an elongation factor counted as a ratio of length of rectangle sides.

For estimating an area error you can use a simplified formula based on substituting our figure by a regular polygon. This formula looks as follow:

$$
\sigma_{S}=\sigma_{B}\left(1-\frac{1}{n}\right) \sqrt{S \sin \left(\frac{2 \pi}{n}\right)}
$$

On the basis of many considerations it was confirmed that for a small number of vertices (less than 40) errors achieved from a formula (15) are too small (from experience) and keeping with that an author of this elaboration applied a modified formula:

$$
\sigma_{S}=\sigma_{B}\left(1+\frac{1}{n}\right) \sqrt{2 S \frac{\pi}{n}}
$$

As in formula (14) there is only a point location error, a value of an area and an elongation factor, then in a formula (16) estimated error of indicated area depends on an area, point location error and numbers of measured points.

\section{Measurement Experiment}

In order to verify some theoretical thesis a measurement experiment has been proceed. A test field has been indicated on a green grass between buildings on campus territory of University of Agriculture in Krakow-Mydlniki (Fig. 3). A border of this grass is not precisely marked. A grass is limited by a soil - surfaced road covered by break stone.

Geodetic measurements has been proceed in two different methods. Pole method measurement has been proceed within 2 months of Total Station Leica TC605. 


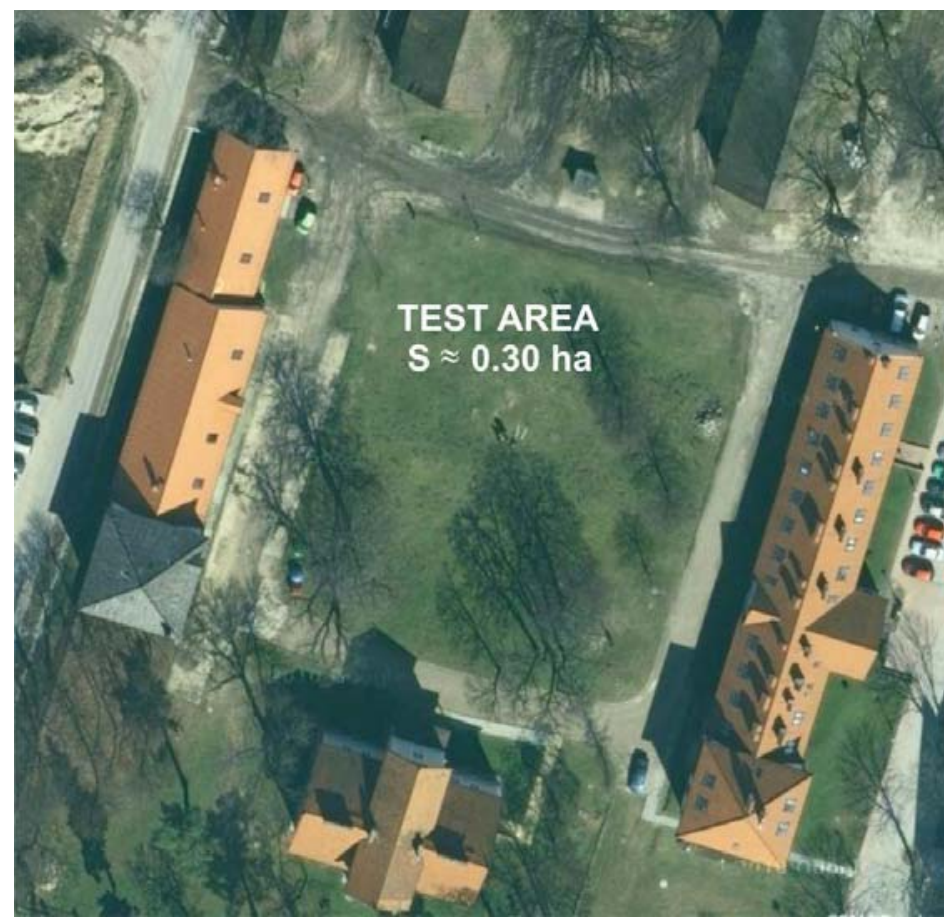

Fig. 3. View of test area (MGGP Aero)

There were groups of two or three people involved in the measurements. In general 65 measurements have been proceed, two of them have been rejected because of serious errors.

A measurement consists of setting a device in the Centre of the test field more or less and registering the location of measurement points (moved mirrors) along the border of a fields. For analysis it was accepted that an error of point location from this measurement has been $\pm 0.05 \mathrm{~m}$.

A second measurement has been done within one week using of six pieces of navigation receivers Garmin GPSmap76 [12]. Also, in this case there were groups of two or three people (but completely different persons than in the first case). A measurement consists of moving along the border of the test field and registering a trace.

Obtained results has been written down:

- an area,

- numbers of measured points,

- accuracy of receiver.

It is necessary to pay attention to the fact that in navigation receivers during measurements with trace applications, a displayed area is indicated only on the basis of registered trace points. That means even when the function of receiver allocation in fixed interval of time, e.g. each second is switched on - in computation of 
an area these points are not taken into consideration. Measurements in fixed interval of time can be considered in computation in a secondary way after the data is transferred into a computer in the office. In general 51 GPS measurements has been processed, unfortunately only 38 has been accepted for further analysis (13 of them were rejected because of observer errors, e.g. trace registering has not been switched off after measuring). An average error of location point in this method achieved in GPS receiver was $\pm 1.6 \mathrm{~m}$.

\section{Results of Analysis}

As a result of measurements we have two types of observation. Figure 4 shows marked values of indicated areas of tested parcel depending on numbers of points measured on the edge.

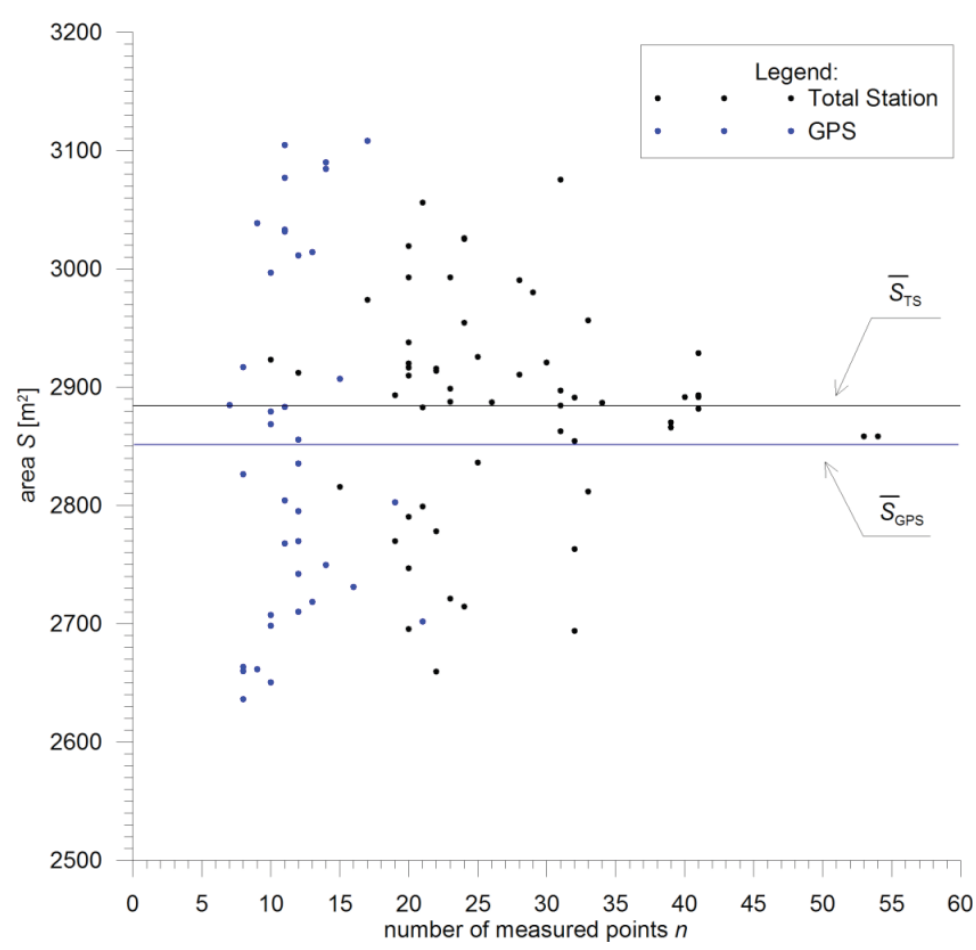

Fig. 4. Results of area measurement

Data placed on figure 4 shows that measurements done with satellite receivers are more dispersed that done with Total Station. Measurements done with Total Station engaged more points from the edge of measured area. 
Measurement results were elaborated separately for each method of measuring. An average value, an standard deviation and average value standard deviation were found from standard dependency:

$$
\begin{gathered}
\bar{S}=\frac{\sum_{j=1}^{m} S_{j}}{m} \\
\sigma_{S}=\sqrt{\frac{\sum_{j=1}^{m}\left(S_{j}-\bar{S}\right)^{2}}{(m-1)}} \\
\sigma_{\bar{S}}=\sqrt{\frac{\sum_{j=1}^{m}\left(S_{j}-\bar{S}\right)^{2}}{(m-1) m}}
\end{gathered}
$$

where:

$m$ - number of observation,

$j$ - symbol of next observations.

A computation results according to above formulas are presented in table 1.

Table 1. Results of statistical calculation

\begin{tabular}{|c|c|c|c|}
\hline Type of calculation & Symbol & Total Station & GPS \\
\hline \hline \multirow{4}{*}{ Statistics } & median & 24 & 11 \\
\cline { 2 - 4 } & $S_{\max }$ & 3075.6 & 3108.3 \\
\cline { 2 - 4 } & $S_{\min }$ & 2659.6 & 2636.0 \\
\hline \multirow{4}{*}{ Equal accuracy } & $\bar{S}$ & 2884.8 & 2853.1 \\
\cline { 2 - 4 } & $\sigma_{\bar{s}}$ & 11.1 & 24.4 \\
\cline { 2 - 4 } & $\sigma_{S}$ & 87.8 & 150.2 \\
\hline \multirow{3}{*}{ Weighting observation } & $\bar{S}_{w}$ & 2884.2 & 2856.2 \\
\cline { 2 - 4 } & $\sigma_{\bar{s}_{w}}$ & 10.8 & 24.4 \\
\cline { 2 - 4 } & $\max$ & 112.4 & 174.5 \\
\cline { 2 - 4 } & $\min$ & 70.9 & 93.0 \\
\hline \multirow{3}{*}{ Theoretical error (16) } & $\max$ & 2.4 & 47.6 \\
\cline { 2 - 4 } & $\min$ & 0.9 & 126.9 \\
\hline
\end{tabular}

Analysis of observations schedule placed at figure 4 brought the conclusion that together with growth of measured points a dispersion of results get more narrow so the decision was to make weighting (of measurements). 
For this purpose a formula (16) was used and after some conversions the following dependency was obtained:

$$
w_{j}=\frac{\sqrt{n^{3}}}{n+1}
$$

Formulas for computation an average value and an error of average value can be written this way:

$$
\begin{gathered}
\bar{S}_{w}=\frac{\sum_{j=1}^{m} S_{j} w_{j}}{\sum_{j=1}^{m} w_{j}} \\
\sigma_{\bar{S}_{w}}=\sqrt{\frac{\sum_{j=1}^{m}\left(S_{j}-\bar{S}_{w}\right)^{2} w_{j}}{(m-1) \sum_{j=1}^{m} w_{j}}}
\end{gathered}
$$

an average error of the following weights of observation can be found from dependency:

$$
\sigma_{S_{j}}=\sqrt{\frac{\sum_{j=1}^{m}\left(S_{j}-\bar{S}_{w}\right)^{2} w_{j}}{(m-1) w_{j}}}
$$

The results of measurements presented at figure 4 and table 1 shows a large dispersion of area measurements placed along allotment borders, obtained between several observations. Using formulas for errors indication of an average observation (16) show that generating error factors must have occurred and were independent from measurement devices. Supposedly, an important element which influences the accuracy of measurements is proper identification of the measured area border and reliable measuring operations.

\section{Indication of Measurements Accuracy}

As a result of direct inspections of crop areas there were found some divergences between declared area and obtained during inspection. In 2004 in Poland about $15 \%$ of irregularities was found and in 2005 about $13 \%$ in declared areas [5].

According to European Commission guidelines [8] there is an allowable tolerance between area declared by farmer and area indicated during direct inspection. Allowable tolerance (relative error of area) is $5 \%$ of area [14]. So we can put down:

$$
\delta_{S}=\frac{\sigma_{S}}{S} \leq 5 \%
$$


Indicated tolerance consists of inspection accuracy and accuracy of area declared by agriculture producer, according to:

where:

$$
\delta_{S}^{2}=\delta_{m}^{2}+\delta_{a}^{2}
$$

$\delta_{m}$ - relative error of inspected area,

$\delta_{a}$ - relative error of declared area.

If we do not know a source of possible errors concerning measurements and declaration we should make an assumption they exist in the same proportions. In such a case considering (24), relative error of measurement during inspection can be:

$$
\delta_{m}=\delta_{a}=0.7071 \delta_{S} \leq 0.035 S
$$

We should take into consideration - what was proved before - that relative error of area inspection can be caused by technology and choice of devices and also wrong identification of measured area borders. Relative to dependency (16) it is possible to find what should be an accuracy of measurement so that relative error was conformable to (26). After conversions it is obtained:

$$
\sigma_{B} \leq 0.014 \frac{\sqrt{n^{3} S}}{1+n}
$$

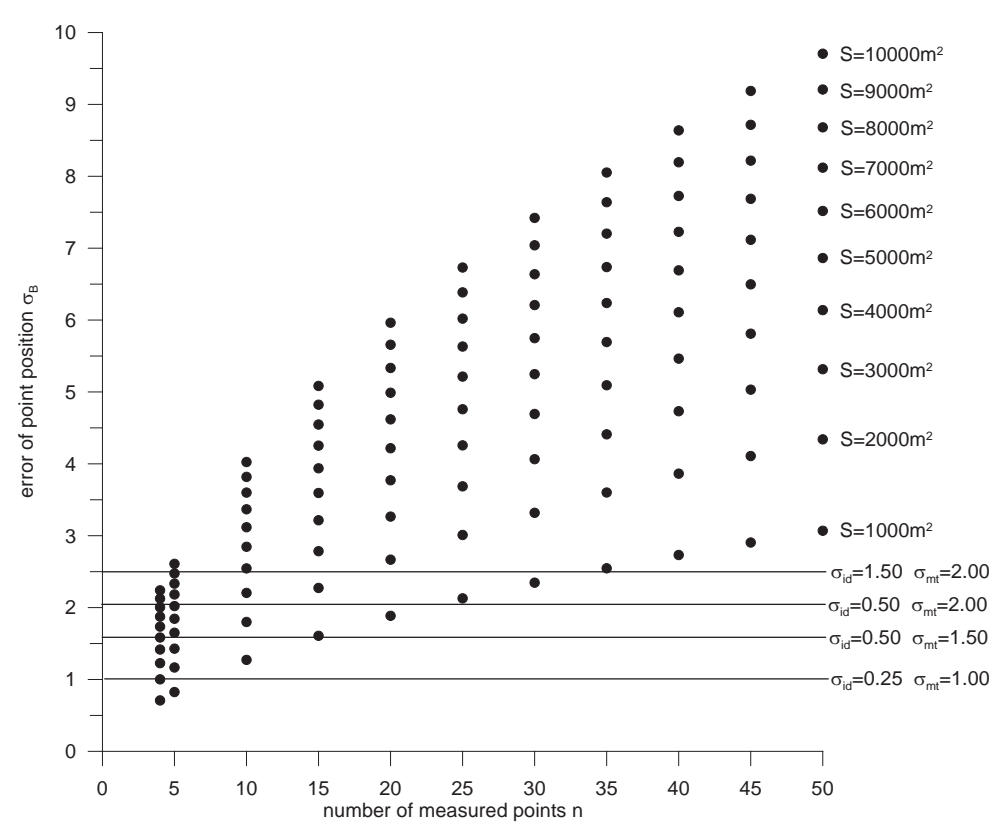

Fig. 5. Chart of boundary point position error 
Figure 5 presents limiting value of error in point location according to dependency (27). Limiting errors of a various number of points location are marked pointwise along the border and various area values. Errors in point location caused by wrong border identification $\left(\sigma_{i d}\right)$ and errors of measurement method $\left(\sigma_{m t}\right)$ are marked by lines.

Results presented on the diagram show that limiting error of a location point depends on measured allotment area and numbers of measurement along its borders.

\section{Summary}

Each year in the European Union a large number of control measurements of crops area are carried out. This is done for registry reasons. Control measurements of crops are the basis of paying off the subsidies to agriculture. There is a big error margin between declared area and measured during inspection.

The important factor during control measurement of crops area declared by farmer which is proper identification of borders between different crops. For some of them identification is quite simple while other are difficult and full of doubts. For this reason it is not reasonable to require high accuracy of measurement from geodesists. Important is to know how to find the right borders.

During control measurement needed for subsidies to agriculture reasons some navigation devices based on satellite systems are used. These type of devices are not common in geodesy but in parcel area measurement where high accuracy is not required they can be successfully applied.

In this publication some measurement results of allotment area doe with GPS and Total Station were compared. Confronted results shows that one of the main factors is proper identification of area border in territory. An error value caused by choice of navigation receivers in the analyzed case is about half of total measurement error value, another part of the error seems to be caused by irregularities which can always occur in the measuring operation. Basic factors which generate errors in location point are: improper border identification, lack of reliability in operations, rush and other time requirements during measurement.

\section{References}

[1] Alkan R.M., Saka M.H.: A Performance Analysis of Low-Cost GPS Receivers in Kinematic Applications. The Journal of Navigation, vol. 62, 2009, pp. 687-697.

[2] Alnaqbi A., El-Rabbany A.: Precise GPS Positioning with Low-Cost Single-Frequency System in Multipath Environment. The Journal of Navigation, vol. 63, 2010, pp. 301-312.

[3] Barry B.A.: Errors in Practical Measurement in Science, Engineering, and Technology. John Wiley \& Sons, New York 1978. 
[4] Bogaert P., Delince J., Kay S.: Assessing the error of polygonal area measurements: a general formulation with applications to agriculture. Measurement Science and Technology, vol. 16, 2005, pp. 1170-1178.

[5] Buśko M., Dukielski P., Krzyżek R.: Wybrane zagadnienia kontroli gospodarstw rolnych w ramach programu IACS (Integrated Administration and Control System). Geomatics and Environmental Engineering, vol. 1, no. 3, 2007, pp. 77-88.

[6] Chandra A.M.: Plane Surveying. New Age International, 2006.

[7] Chrisman N.R, Yandell B: Effects of point error on area calculations. Surveying and Mapping, vol.48, no. 4, 1988, pp. 241-246.

[8] COMMISSION REGULATION (EC) No. 796/2004: Laying down detailed rules for the implementation of cross-compliance, modulation and the integrated administration and control system provided for in of Council Regulation (EC) No 1782/2003 establishing common rules for direct support schemes under the common agricultural policy and establishing certain support schemes for farmers.

[9] Dąbrowski K., Plewako M.: Zastosowanie odbiorników GPS z korekcją różnicowa EGNOS do pomiaru pól powierzchni działek rolnych. Zeszyty Naukowe Akademii Rolniczej w Krakowie, nr 438, Geodezja, z. 24, 2007, pp. 37-45.

[10] Doskocz A.: Dokładność obliczania pola powierzchni ze wspótrzędnych płaskich. Materiały III Ogólnopolskiej Konferencji Naukowo-Technicznej “Kartografia numeryczna i informatyka geodezyjna”, Rzeszów - Solina 2009, pp. 75-86.

[11] El-Rabbany A.: Introduction to GPS. The Global Positioning System. Artech House, 2002.

[12] GPSmap 76 chartplotting receiver. Owner's manual. Garmin International, Olathe 2006.

[13] Ghilani C.D., Wolf P.R.: Elementary Surveying: An Introduction to Geomatics. Pearson Education, 2008.

[14] Hejmanowska B.: Wpływ jakości danych na ryzyko procesów decyzyjnych wspieranych analizami GIS. Rozprawy Monografie nr 141, Uczelniane Wydawnictwa Naukowo-Dydaktyczne AGH, Kraków 2005.

[15] Hejmanowska B., Woźniak W.: Influence of the number of measured parcel boundary points on the accuracy of land parcel area calculation. Archiwum Fotogrametrii, Kartografii i Teledetekcji, vol. 20, 2009, pp. 123-133.

[16] Kwinta A., Szeptalin A.: Wykorzystanie ręcznych odbiorników GNSS do pomiarów powierzchni działek rolnych. Infrastruktura i Ekologia Terenów Wiejskich, nr 6, 2010, pp. 157-166.

[17] Mika M.: Geodezyjne, prawne i organizacyjne aspekty Jednolitego Systemu Płatności Obszarowej w Polsce. Geomatics and Environmental Engineering, vol. 1, no. 2, 2007, pp. 77-88.

[18] Roy S.K.: Fundamentals of Surveying. Publ. PHI Learning Pvt, 2004.

[19] Schwieger V., Glaser A.: Possibilities of Low Cost GPS Technology for Precise Geodetic Applications. FIG Working Week 2005 and GSDI-8 "From Pharaohs to Geoinformatics", Cairo 2005. 